\title{
Quantum-Chemical Study of Mica Dehydroxylation
}

\author{
Tamara I. Shishelova*, \\ Egor L. Lipovchenko and Valentina V. Shulga \\ Irkutsk National Research Technical University \\ 83 Lermontov Str., Irkutsk, 664074, Russia
}

\author{
Received 23.06.2016, received in revised form 12.09.2016, accepted 30.10.2016
}

Mica composites technology provides high-heat raw materials. Natural mica loses the water, it is converted into dehydroxylate, which chemically react with the components of the binder.

Understanding the mechanism of dehydroxylation is important in obtaining composite materials based on mica. The physical essence of the mechanism of this phenomenon is not fully disclosed and requires further consideration. Questions is interesting about the intramolecular rearrangements at the stage preceding the process of migration of a proton, an analysis of changes in coordination bonds, the stability of the unit cell of muscovite in dehydroxylation.

The process of dehydroxylation from the standpoint of quantum-chemical model on the example of the unit cell of muscovite. This method is most reliably transmits the geometric parameters, and kinetic characteristics of the surface potential of the intramolecular processes.

The results of quantum-chemical model the unit cell of muscovite evidence of its existence in three isomeric forms with respect to the proton of the hydroxyl groups.

Process of dehydroxylation muscovite is intramolecular regrouping in the hexagonal area of Aloctahedra connected with the preparation of optimal orientation of migratory groups or atoms. Transition from one proton of the hydroxyl group to another to form a molecular water leads to migration of water molecules, which means that the field of octahedral aluminum atoms change their coordination number from 6 to 5.

Keywords: quantum chemistry, dehydroxylation, muscovite.

Citation: Shishelova T.I., Lipovchenko E.L., Shulga V.V. Quantum-chemical study of mica dehydroxylation, J. Sib. Fed. Univ. Eng. technol., 2016, 9(7), 1097-1103. DOI: 10.17516/1999-494X-2016-9-7-1097-1103.

(C) Siberian Federal University. All rights reserved

* Corresponding author E-mail address: tamara.shishelova@gmail.com 


\title{
Квантово-химические исследования \\ процесса дегидроксилации слюд
}

\author{
Т.И. Шишелова, Е.Л. Липовченко, В.В. Шульга \\ Иркутский национальный исследовательский \\ технический университет \\ Россия, 664074, Иркутск, ул. Лермонтова, 83
}

\begin{abstract}
Технология слюдокомпозитов предусматривает высокотемпературный нагрев исходных материалов. Природная слюда, утрачивая воду, переходит в дегидроксилат, который вступает в химическое взаимодействие с компонентами связующего.

Понимание механизма дегидроксилации важно при получении композиционных материалов на основе слюд. Физическая сущчность механизма этого явления раскрыта далеко не полностью и требует дальнейших рассмотрений. Интересны вопросы о внутримолекулярных перегруппировках на стадии, предшествующей процессу миграции протона, анализ изменения координационных связей, устойчивости элементарной ячейки мусковита в процессе дегидроксилациии.

Рассмотрен процесс дегидроксилации с точки зрения квантово-химической модели на примере элементарной ячейки мусковита. Этот метод наиболее надежно передает геометрические параметры, кинетические характеристики и потенциальные поверхности внутримолекулярных процессов. Полученные результаты квантово-химической модели элементарной ячейки мусковита свидетельствуют о ее сущчествовании в трех изомерных формах относительно протонов гидроксильных групп.

Процесс дегидроксилацчии мусковита - это внутримолекулярные перегруппировки в гексагональной области Al -октаэдров, связанные с подготовкой оптимальной ориентации мигрирующих групп или атомов.

Переход протона от одной гидроксильной группы к другой с образованием молекулярной воды приводит к миграции молекул воды, из чего следует, что атомы алюминия октаэдрической области изменяют свое координационное число с 6 до 5.
\end{abstract}

Ключевье слова: квантовая химия, дегидроксилация, мусковит.

Успехи науки в области материаловедения привели к созданию нового класса материалов, так называемых композиционных. Свойства новых материалов обладают рядом важных физико-химических характеристик и имеют несомненные преимущества по сравнению с традиционными $[1,2]$.

С самого начала цель создания композитов состояла в том, чтобы достичь комбинаций свойств, не присущих каждому из исходных материалов в отдельности. Из огромного числа композиционных материалов, созданных в последние годы, особое место занимают композиты на основе слюды, сочетающие в себе высокие диэлектрические свойства с механической, химической и термической стойкостями.

Современная технология слюдокомпозитов предусматривает высокотемпературный нагрев исходных материалов. В таких условиях природная слюда, утрачивая воду, переходит в соответствующий дегидроксилат, который при последующем горячем прессовании вступает в химическое взаимодействие с компонентами связующего вещества с образованием различных химических соединений [3, 4]. 
Понимание механизма образования дегидроксилата важно для корректной оценки, прежде всего термической стойкости слюд, а также выявления механизма межфазовых взаимодействий рассматриваемых веществ при получении композиционных материалов на основе слюд.

Несмотря на то что изучению эффекта дегидроксилации посвящено большое количество работ, физическая сущность механизма этого явления раскрыта далеко не полностью и требует дальнейших рассмотрений. Ранее в работах $[5,6]$ с позиции квантовой механики рассмотрен механизм дегидроксилации минералов. Процесс гидроксилации представлен как процесс делокализации протона в системе «два атома кислорода и протон между ними». Такое перемещение протона обусловлено его переходом в возбужденное состояние. При нагреве происходит увеличение энергии протона, в связи с этим растет прозрачность среднего барьера. Учтено и наличие туннельного эффекта - наличие вероятности перехода частицы сквозь барьер. Показано, что имеется возможность оценить степень дегидроксилации по уменьшению интенсивности полос ОН.

Остается интересным вопрос, с чего начинается дегидроксилация, т.е. вопрос о рассмотрении внутримолекулярных перегруппировок, связанных с изометрией гидроксильных групп на стадии, предшествующей процессу миграции протона, анализ изменения координационных связей, оценка относительной устойчивости элементарной ячейки мусковита в процессе дегидроксилации.

Анализ литературных данных показал, что в этом плане перспективным представляются работы, относящиеся к построению квантово-химических моделей [5, 7-14]. При наличии такого рода моделей проще изучать свойства разнообразных минералов [3-4].

Следует признать, что большое количество факторов (природа минерала, размеры частиц и т.д.) оказывают влияние на процесс дегидроксилации и приводят к огромному многообразию полученных экспериментальных данных [6]. В данном вопросе до сих пор нет окончательной ясности.

Актуальными и перспективными представляются работы, посвященные квантовохимическим исследованиям свойств алюмосиликатов и термостойкости различных слюд.

Рассмотрен процесс дегидроксилации с точки зрения квантово-химической модели на примере элементарной ячейки мусковита. Этот метод, позволяющий изучить большой круг проблем, используется в последнее время довольно широко. Поэтому имеется принципиальная возможность использовать его и для исследования процесса дегидроксилации слюды. Данный метод наиболее надежно определяет геометрические параметры, кинетические характеристики и потенциальные поверхности внутримолекулярных процессов. Некоторые варианты этого метода дают хорошие результаты для молекулярных систем с водородными связями.

Известно [2, 13-15], что термически активируемая реакция дегидроксилации в мусковите в температурном интервале до $800^{\circ} \mathrm{C}$ является обратимой. Это указывает на то, что в данном температурном интервале кристаллическая решетка, а в особенности ее тетраэдрические слои, не претерпевают каких-либо существенных изменений. Это возможно только в том случае, если все координатные связи тетраэдрической сетки с гексагональной $A \ell$-октаэдрической сеткой остаются неизменными. Поэтому не без основания можно полагать, что в процессе деги- 
дроксилации в указанном температурном интервале претерпевают изменения только водородные и координатные связи алюминий-гидроксильной группы.

В процессе дегидроксилации в указанном температурном интервале претерпевают изменения только водородные и координационные связи алюминий-гидроксид.

Нами была проведена следующая работа:

- были рассмотрены внутримолекулярные перегруппировки, связанные с изометрией гидроксильных групп на стадии, предшествующей миграции протона;

- проведена оценка потенциальных функций внутримолекулярного переноса протона и образования связанной молекулы воды;

- сделан анализ полученных активационных параметров процесса и их сопоставление с прочностью координационной связи гидроксид-алюминий для выявления возможности внутримолекулярной миграции гидроксильной группы и образования связанной воды;

- осуществлен анализ изменения координационных связей в гексагональной $A \ell-$ октаэдрической области;

- дана оценка относительной устойчивости элементарной ячейки мусковита до и после процесса дегидроксилации.

Стартовые геометрические параметры элементарной ячейки идеальной модели мусковита взяты из рентгеноструктурных данных [5, 6].

Квантово-химические расчеты проведены с частичной оптимизацией геометрии по критерию полной энергии. В процессе оптимизации участвовали внутренние геометрические параметры гексагональной $A \ell$-октаэдрической области. Схема, по которой проведено исследование процесса дегидроксилации, изображена на рис. 1, для большей наглядности приведена только центральная $A \ell$-октаэдрическая часть элементарной ячейки, принимающей наиболее активное участие в данной реакции. Возможность образования кристаллических изомеров за счет поворотной изометрии гидроксильных групп (рис. 2) делает необходимой оценку их относительной устойчивости, путей взаимных переходов и влияния, которое оказывает изомерная форма на процесс дегидроксилации в целом.

Среди большого многообразия поворотно-изомерных форм можно выделить три наиболее устойчивые структуры, разделенные достаточными активационными барьерами внутренних взаимных переходов, исключающих их свободное взаимопревращение. Это формулы с транстранс(1a), цис-транс(1б) и цис-цис(1в) взаимным расположением протонов гидроксильных

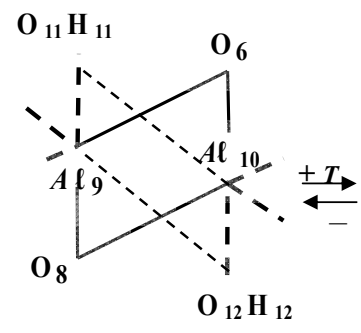

I

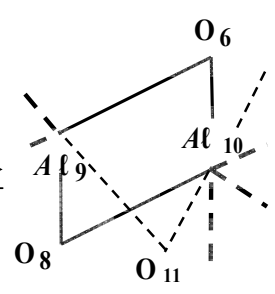

II

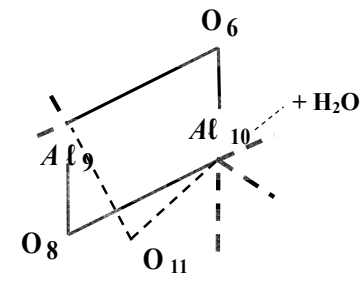

III

Рис. 1. Общая схема процесса дегидроксилации, рассматриваемая в расчетах (представлена только $\mathrm{A \ell -}$ октаэдрическая область) 


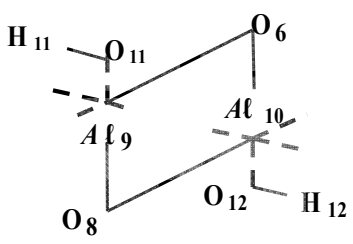

1a

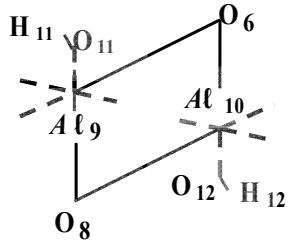

16

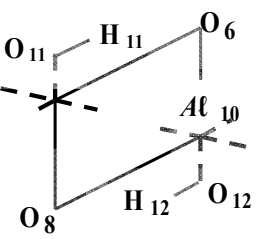

1в

Рис. 2 Схематическое представление наиболее устойчивых изомерных форм центральной $\mathrm{A \ell -}$ октаэдрической области элементарной ячейки мусковита
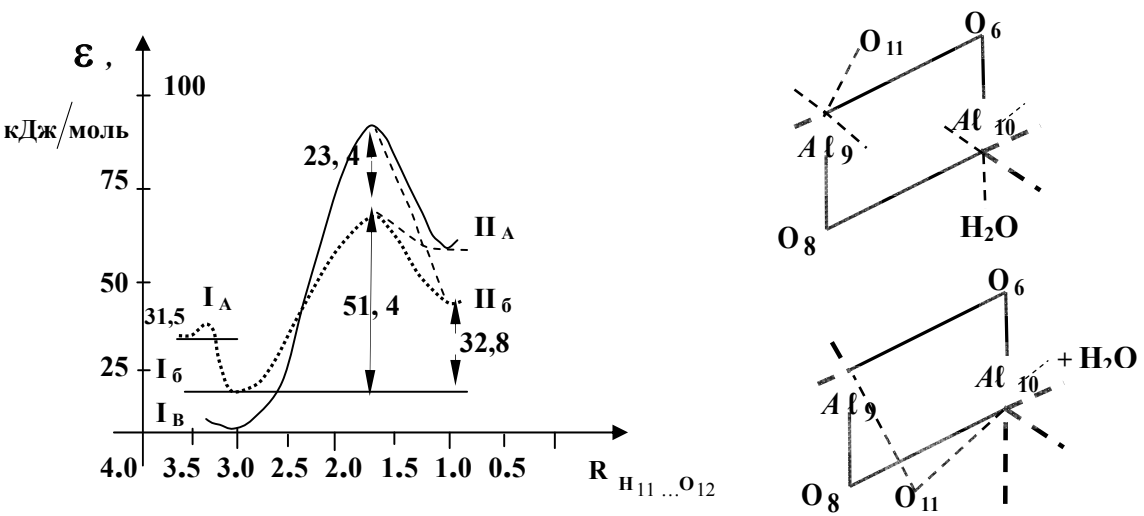

Рис. 3. Потенциальная функция внутреннего переноса протона

групп (рис. 2). Квантово-химические расчеты показали, что форма 1а наименее устойчива по сравнению с 16 на 4,1 ккал/моль по сравнению с 1в (рис. 3).

Активационные параметры внутренних переходов 1а-1б и 1б-1в различаются незначительно и составляют 8,30 кДж/моль и 10,9 кДж/моль соответственно. Предпочтительность цис-транс-формы 16 по сравнению с транс-транс-формой 1а объясняется образованием водородной связи $0_{11} \ldots \mathrm{H}_{12}$ с межатомным расстоянием 0,315 нм и энергией водородной связи, равной 5,34 кДж/моль, а также уменьшением невалентных взаимодействий протона $\mathrm{H}_{12}$ в цис- по сравнению с транс-положением. Этот выигрыш составляет примерно 8,3 кДж/моль. Еще более благоприятная картина в смысле уменьшения невалентных взаимодействий наблюдается в цисцис-форме 1в, что и делает ее наиболее устойчивой по сравнению с изомерами 1а и 16. На рис. 3 приведены потенциальные функции внутримолекулярного переноса от одной гидроксильной группы к другой, в качестве одной из осей координат выступает полная энергия молекулярной системы, в качестве другой - межатомное расстояние $0_{11} \ldots \mathrm{H}_{12}$. Внутримолекулярный перенос протона для переходов $16-П$ и 1 в-П осуществляется в расчетах по прямой $0_{11} \ldots \mathrm{H}_{12}$ с шагом 0,3 А, в каждой точке проводилась корректировка внутренних геометрических параметров $A \ell-$ октаэдрической области.

Более высокий барьер перехода 1в-П по сравнению с 1б-П объясняется дополнительной внутренней перестройкой, связанной с внутренним вращением связи $\mathrm{H}-0_{12}$ вокруг координационной связи $0_{12} \ldots$ Al (вынужденная цис-транс-изометрия). 
В результате миграции протона прототропная форма П-а не является с точки зрения минимума полной энергии оптимальной и переходит в более устойчивую П-б-форму (рис. 3). Эта форма характерна тем, что лишенный протона атом кислорода занимает такое положение, при котором он образует две равноценные координационные связи с атомами $A \ell_{9}$ и $A \ell_{10}$. Межатомное расстояние $\mathrm{H}_{2} 0 \ldots A \ell_{10}$ Увеличивается при этом с 0,189 до 0,211 нм. Угол, образованный плоскостью $0_{6} A \ell_{10} 0_{8}$ и связью $A \ell_{10} \ldots \mathrm{OH}_{2}$, также увеличивается со $101^{\circ}$ до $116^{\circ}$, т.е. происходит выталкивание связанной молекулы $\mathrm{H}_{2} 0$ за пределы внутренней части элементарной ячейки.

Особенностью конечной дегидратированной структуры является пентакоординированный характер атомов $A \ell_{9}$ и $A \ell_{10}$. Это устойчивое состояние с эквивалентными пентакоординированными атомами алюминия единственное. Расчеты, выполненные с нарушением эквивалентности этих атомов, не приводят к стационарным состояниям.

Для выявления возможности внутримолекулярной миграции гидроксильных групп оценена прочность координационной связи гидроксил-алюминий как двуцентровой составляющей полной энергии. Полученное значение $\mathrm{E} \approx 167$ кДж/моль свидетельствует о том, что этот механизм не конкурентоспособен механизму протонной перегруппировки (рис. 3).

Полученные таким образом результаты изученной квантово-химической модели элементарной ячейки мусковита позволяют сделать следующие выводы:

1. Элементарная ячейка может существовать в трех изомерных формах относительно протонов гидроксильных групп. Эти формы близки по энергии и довольно легко переходят из одной формы в другую.

2. Процесс дегидроксилации мусковита можно рассмотреть как совокупность трех наиболее вероятных этапов:

- внутримолекулярные изомерные перегруппировки в гексагональной области $A \ell$ октаэдров, связанные с подготовкой оптимальной ориентации мигрирующих групп или атомов, т.е. переход гидроксильных ионов в позиции цис-транс- или в энергетически более выгодную цис-цис-ориентацию;

- переход протона от одной гидроксильной группы к другой с образованием молекулярной воды, связанной с элементарной ячейкой;

- миграция молекул воды к периферии кристалла по тетраэдрическим каналам через свободные ячейки с образованием промежуточных водородных связей (сорбированная вода). Образование в кристалле связанной воды может осуществляться только за счет прототропных перегруппировок;

- в процессе дегидроксилации атомы алюминия октаэдрической области изменяют свое координационное число с 6 до 5.

\section{Список литературы:}

[1] Шишелова Т.И. Слюдосодержащие композиционные материалы: дис. ... д-ра техн. наук. Ленинград, 1990, 350 c. [Shishelova T.I. Mica composites. Diss. Doctor of Technical Sciences, Leningrad, 1990, 350 p. (in Russian)].

[2] Шишелова Т.И., Тюрин Н.Г., Чайкина Е.А., Леонов С.Б. Физико-химические основы производства слюдокомпозитов. Екатеринбург, Ладъ, 1993, 212 с. [Shishelova T.I Tyurin N.G, 
Chaikin E.A, Leonov S.B. Physical and chemical bases slyudokompozitov. Production Yekaterinburg: Publishing House of the «Lad», 1993, 212 p. (in Russian)].

[3] Мецик М.С. Физика расщепления слюд. Иркутск, В-С. кн. изд-во, 1967, 208 с. [Metsik M.S. Physics splitting mica. Irkutsk B-C. Vol. Publishing House, 1967, 208 p. (in Russian)].

[4] Шишелова Т.И. Вода в минералах. Иркутск, Изд-во ИрГТУ, 2011, 112 с. [Shishelova T.I. Water in minerals: monograph. Irkutsk: Irkutsk State Technical University Publishing House, 2011, 112 p. (in Russian)].

[5] Шишелова Т.И., Липовченко Е.Л. Механизм дегидроксилации минералов с позиций квантовой механики. Фундаментальные исследования. 2015. №.6. Ч. 2. С. 311-315. [Shishelova T.I, Lipovchenko E.L. Mechanism degidroksilatsii minerals from the standpoint of quantum mechanics. Fundamental research. №.6. Part 2. 2015, pp 311-315. (in Russian)].

[6] Vedder W., Wilkins R.W.T. Dehydroxylation and rehydroxylation, oxidation and reduction of micas. American Mineralogist. 1969, 54. C. 482-509.

[7] Блатов В.А., Шевченко А.П., Пересыпкина Б.В. Полуэмпирические расчётные методы квантовой химии. Самара: Универс-групп, 2005, 32 с. [Blatov V.A, Shevchenko A.P, Peresypkina B.V. Semi-empirical computational methods in quantum chemistry. Samara: Univers Group, 2005, 32 p. (in Russian)].

[8] Новосадов В.К. Методы решения уравнений квантовой химии. М.: Наука, 1985, 183 с. [Novosadov V.K. Methods for solving the equations of quantum chemistry. M .: Nauka, 1985, 183 p. (in Russian)].

[9] Степанов Н.Ф. Квантовая механика и квантовая химия. М.: Мир, 2001, 519 с. [Stepanov N.F. Quantum mechanics and quantum chemistry. M .: Mir, 2001, 519 p. (in Russian)].

[10] Степанов Н.Ф., Пупышев В.И. Квантовая механика и химия. М.: Изд-во МГУ, 1991, 384 c. [Stepanov N.F., Pupyshev V.I. Quantum mechanics and chemistry. M .: MGU, 1991, 384 p. (in Russian)].

[11] Фларри Р. Квантовая химия. Введение. М.: Мир, 1985, 472 с. [Flarri R. Quantum Chemistry. Introduction. M .: Mir, 1985, 472 p. (in Russian)].

[12] Мотт Н., Снеддон И. Волновая механика и её применения. М.: Изд-во КОМКНИГА Теоретическая физика, 2007, 432 c. [Motte N., Sneddon I. The wave mechanics and its application. M .: KomKniga in Theoretical Physics, 2007, 432 p. (in Russian)].

[13] Шишелова Т.И., Мецик М.С., Соколов К.Я. Изменение ИК-спектров слюд при нагревании. Журнал прикладной спектроскопии. 1974, Т. 20 . Вып.6. С. 1042-1044. [Shishelova T.I., Metsik M.S., Sokolov K.Y. Changes in the IR spectra of mica by heating. Journal of Applied Spectroscopy. 1974, T. 20. Vyp.6. Pp 1042-1044. (in Russian)].

[14] Балашов В.В., Долинов В.К. Курс квантовой механики. Ижевск: НИЦ “Регулярная и хаотическая динамика". 2001, 336 c. [Balashov V.V., Danilov V.K. The course of quantum mechanics. Izhevsk Research Center «Regular and chaotic dynamics». 2001, 336 p. (in Russian)].

[15]Шишелова Т.И., Мецик М.С., Соколов К.Я. Исследование дегидратащии слюд и слюдопластовых материалов методом ИК-спектроскопии. тр. ИПИ. Иркутск : Изд-во ИПИ, 1972, Вып.7. С. 15-17. [Shishelova T.I., Metsik M.S.,Sokolov K.Y. Research dehydration mica and slyudoplastovyh materials by IR spectroscopy. tr. FPI. Irkutsk: Publishing House of the FPI, 1972, 7. P. 15-1. (in Russian)]. 